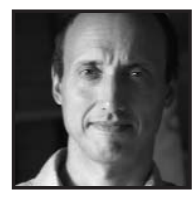

\title{
Multiple Definitions of Reading: Why They Continue to Be Used in the Same Contexts, and What This Has Meant for Literacy Instruction
}

\author{
Paul Kettner, English Montreal School Board
}

\section{ABSTRACT}

What literacy means has evolved significantly in recent decades, but even in the context of Quebec, where the provincial curriculum embraces a forward-thinking definition of literacy, multiple understandings of literacy and reading coexist within the same community. This article argues that how the concepts of reading and literacy are understood, and how best to teach them, continues to be framed within the boundaries set out by traditionally opposing research paradigms, and that these frameworks have further complicated the challenge of helping students become strong readers of print. With a specific focus on the reading of print, this article examines how these understandings differ and what this has meant for reading and literacy instruction. It is argued that a rethinking of the way that research informs pedagogy may further the benefits that the researcher-practitioner relationship brings to classroom practice.

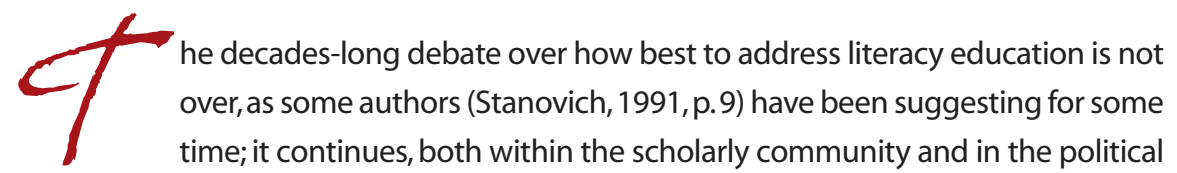
arena of policy-making situated in government bodies and school-board offices. In part, this is because literacy is a slippery topic; it means different things to different people. This is true within the Quebec context, where the provincially determined curriculumnow more than a decade old-clearly embraces a very forward-thinking definition of literacy. Even within this context, however, there remains a degree of confusion. 
Helping students develop as strong readers of print remains the dominant concern for many teachers in spite of a mandate to address a broader concept of literacy. Teachers face a complicated debate that involves disagreement about what literacy means while still struggling with more traditional conflicts about how best to teach it. There are several reasons for this. Most familiar perhaps are the polarized views expressed in the "great debate" (Chall, 1967) between a code-breaking emphasis (Gough, 1980; Liberman \& Shankweiler, 1991; Perfetti, 1991; Stanovich, 1991) and a whole language approach (K. S. Goodman \& Y. M. Goodman, 1979; Newman, 1985; Smith, 2004) to the teaching of literacy. But there is more at issue in this debate than pedagogy; it is also about competing notions of what we understand literacy to be, and what functions we expect it to serve. This is a debate that is defined by differing, often opposing research paradigms (Foorman, 1995; Weaver, 1998a) and by the social and political tenor of the time. And so, while we see literacy commonly referring to the ability to decode and make sense of print texts (Gough, 1980; Liberman \& Shankweiler, 1991), we also see it defined in broader terms, as a socio-cultural process involving a complex set of behaviours that allow individuals to engage with the social world around them, to understand and communicate their own perspectives of the world (K. S. Goodman \& Y. M. Goodman, 1979; Halliday, 1978; Smith, 2004). Clearly, this debate is driven in part by the opposing approaches of different research paradigms (Aoki, 1984; Stanovich, 1991; Weaver, 1998b); however, it is also clear that the existence of different meanings of literacy and, more specifically, reading commonly being employed complicates the issue. The often-opposing pedagogical approaches to teaching literacy, and the divergent research paradigms that support them, have unnecessarily hindered efforts at finding a balance when it comes to instruction, leaving teachers to make sense of contradictory advice. The central purpose of this paper is to clarify how differing concepts of reading are understood, and what these various understandings mean for practice under the broader umbrella of literacy within Quebec schools. I argue that while our priority must remain the teaching of literacy viewed as a natural, socio-cultural process of communication and meaning-making through a variety of modes-literacy as it is viewed within the Quebec Education Program - we can still attend to the teaching of print reading as a vital component of literacy, and as a skill that requires some explicit instruction. The ongoing shift in recent years in favour of a balanced approach to literacy instruction demonstrates that pedagogies that have been seen as mutually exclusive, even oppositional, can instead be viewed as complementary. Moreover, it provides the opportunity for a reconsideration of the way research has tended to inform pedagogy, allowing for academics and teachers to work collaboratively in reflecting on how students become literate, and, importantly, on what it is that teachers are supposed to teach. 


\section{The Quebec context}

When we speak of literacy, we need to make explicit that it is an evolving term; its newer connotation goes well beyond traditional notions of literacy as a set of skills_-reading and writing at a functional level_-possessed by an individual and acting as a passport of sorts to higher levels of education and work. The Quebec Education Program embraces a more evolved understanding of literacy, establishing at the outset that "the goal of any literacy program must be to provide opportunities for students to experience language as a way of making sense of their experiences and of breaking down barriers that separate individuals" (Ministère de l'Éducation du Québec, 2001, p. 72). The Quebec curriculum frames literacy as complex, as multimodal, as social: what was once a skill or set of skills is now a development of those knowledges that students bring with them; what was once a containable body of material to be passed on to students has been replaced by a set of competencies in which knowledge and social function come together to give purpose to literate behaviours.

Importantly, within the Quebec Education Program, the meanings associated with reading and writing have become more complex and varied as well. They have shifted away from a focus on the reading and production of written language to refer instead to a wide array of language modes. As with the concept of literacy itself, the Quebec curriculum defines texts and reading in far broader strokes than is the case with more traditional approaches that focus on reading and producing print texts. Students are expected, for example, to "read, view, and/or listen to a variety of children's texts" (Quebec, 2001, p. 76). Reading has evolved to include "listening to" and "viewing" texts as well as to reading print, a sophisticated idea that recognizes the ubiquitous presence of texts of many modes and genres in our lives. While it is not the purpose of this paper to examine the story of the evolution of literacy, it is important to understand that the concept of literacy described in the Quebec curriculum finds its roots in a long line of social and educational theorists who have argued that the traditional focus on reading and writing is neither appropriate in a new, multimodal age, nor can it best serve the complex social needs of a diverse and culturally mixed student body.

That the Quebec curriculum embraces a forward-thinking, sophisticated understanding of literacy is not in question. The issue is complicated, however, because this newer concept of literacy has not completely replaced traditional understandings of what literacy means: the two notions coexist within the educational community and our society in general. When parents and politicians speak of literacy, there is the understanding that they are speaking about levels of print 
literacy - they are concerned with how well students learn to read and write print texts. Teachers, too, struggle with this issue. Even teachers who strongly embrace the curriculum reform grapple with the issue of how best to teach students to read print, and, importantly, what portion of the day should be allotted to this goal. Teachers express concern that their students will not thrive in our educational system, or our culture at large, without strong skills in reading and writing print. Indeed, the issue of how best to teach literacy and reading continues to be a topic debated by teachers in Quebec.The issue is even more complicated because it is highly charged politically. That is to say, those teachers who tend to maintain a stronger focus on the reading of print, or who lean more heavily on explicit strategy and skill instruction are viewed, rightly or wrongly, as being more conservative, more traditional. There seems to be, for many people, the sense that certain approaches are strictly exclusive, that, for example, a holistic, broad view of literacy and literacy learning does not dovetail with some regular explicit teaching of certain strategies and skills.

It is useful, in this context, to re-examine some of the arguments that inform discussions around the teaching of literacy in order to clarify why the issue continues to be divisive, and to point out some of the limitations offered by research.

\section{A legacy of disagreement}

A brief look backward demonstrates that the debate regarding how best to define (and teach) reading and literacy has changed very little in the last 40 years. Jeanne Chall (1967) argued that the evidence gathered from the "laboratory, the classroom, and the clinic," (p. 307) over a 50-year period, established that the teaching of reading was in need of a change. Chall's interpretation of the research held that children were more likely to read for meaning when taught with a code-emphasis approach. This result ran counter to the meaning-centered approach's tenet that instruction out of context will not produce real readers. While Chall's study was enormously influential in affecting the objectives of teaching at the elementary grades, many authors argued Chall made errors both in her reporting of the data, and in her conclusions as to how the data should affect pedagogy (Carbo, 1988, p. 228).

This debate has played itself out several times since Chall's work was first published, and the script in each case has varied very little. This occurred most recently, and perhaps most significantly, in the United States following the report of the National Reading Panel (NRP) (2000b). The report was the result of a two-year review of research conducted by a 14-person panel, produced at congressional request to "assess the status of research-based knowledge" in the area of reading 
instruction (National Reading Panel, 2000a, p. 1). The report establishes that the panel set out to review approximately 100,000 studies on reading from 1966 to 2000, and an additional 15,000 prior to 1966 (section 1, p. 1). The panel, in establishing that only experimental or quasi-experimental studies would be examined, noted that this is the same type of evidence used in "psychological and medical research," (National Reading Panel, 2000b, p. 5, section one) making a clear effort to construct a tone of authority, one that carries the greatest weight in advancing the panel's claims. They were very successful in this regard, so much so that a 2001 federal plan recommended that "funding be distributed or withheld based on the district's compliance with the NRP findings" (Garan, Shanahan, \& Henkin, 2001, p. 62). There was a notable increase in pressure following the findings of the report to institute the pedagogy outlined by the panel. These recommendations included, for example, that reading programs should comprise specific instruction to support phonemic awareness (National Reading Panel, 2000a, p. 7); that systematic phonics instruction is a powerful, important tool for reading instruction to be used from kindergarten through grade six (p. 9); that fluency is an important skill in reading development that should be fostered through oral guided reading and independent reading (p. 12); and that properly managed vocabulary instruction leads to gains in comprehension (p. 14).

As in the case of Chall, 33 years earlier, the NRP report was hotly contested on a number of levels. A central criticism levelled at the NRP is the manner in which the panel framed their search at the outset. The strict adherence to experimental, scientific studies resulted in a massive cull of available data: In the case of phonemic awareness, for example, 1,962 citations relevant to the topic were identified by the panel sub-committee. In keeping with the panel's policy, the sub-committee, after "detailed examination," used only 52 studies from the original selection (p. 7), omitting 1,910 studies because they did not conform to the scientific research standard set by the panel. This is not to suggest that the studies that were included were poorly done, or that they fail to offer important insight into the teaching of reading, but that they clearly represent a very small selection of the available data, and exclude a significant amount of important work (Garan et al., 2001, p.62).

As in the case of Chall's work, the considerable effort by the NRP to adhere to strict scientific methodology fanned the flames of contention rather than extinguished them. Numerous attacks were made on the quality of the science itself (see for example, Allington, 2004; Camilli \& Wolfe, 2004; Garan et al., 2001; Krashen, 2001) as well as on the approach. Gregory Camilli and Paula Wolfe express the broad tenor of the complaints against the NRP conclusions, suggesting in effect that it is not that the research used by the panel had nothing important to offer, but that the flawed 
science and narrow window resulted in a misuse of the data. They suggest instead that a more accurate reading of the data might have concluded that "direct instruction in phonics is necessary for certain at-risk kindergarteners, but only if embedded in a print-rich, comprehensive literacy program and delivered in brief individualized lessons" (p. 28). It seems, in sifting through the debates on how best to teach reading, that answers we can be sure of are hard to come by. What is far more certain is that there is a clear connection between the answers that are given and the research paradigm adopted by whoever frames the questions.

\section{Competing evidence, or competing approaches?}

Clearly, the debate over how best to teach literacy is a dispute that is as much about polarized research paradigms as it is about pedagogy, or students themselves, for that matter. Challenging questions are raised as a result. In an article discussing the acquisition and application of knowledge, Wendel Garner begins by suggesting that "in discussions of the sort we are having today, there frequently occurs an impasse, or at least a hesitation, while the discussants come to realize that they are not discussing quite the same thing" (1972, p. 941). Garner is focused here on how research specific to psychology is conceived of and applied, but his point is certainly applicable to the issue of literacy where the shift in the status of a particular research paradigm is paralleled by a shift in pedagogy.

Barbara Foorman (1995) points out that the debate is indeed a clash of paradigms with supporters of code emphasis drawing from cognitive psychology in one camp and whole language enthusiasts in the other from a "constructivist psychology and continental philosophical perspective" (p. 2). The resulting situation, then, is one in which educators who are more firmly embedded in the cognitive psychology camp argue for a bottom-up approach that sees literacy as reading, and reading as a learned skill, instead of the top-down, whole-language view that accepts the notion that reading, as a component of literacy, is a natural and far more complicated process than just decoding (K. S. Goodman \& Y. Goodman, 1979; Newman, 1985). At its core, this is a clash of traditions that govern what kinds of research we choose to accept as valid. Ted Aoki (1986/99) has argued that the dominant intellectual paradigm within North America has been one in which "positivistic science and its derivative technological world view are dominant" (p. 126). And, indeed, if we examine the power of documents such as the report of the National Reading Panel (2000a, 2000b) to influence policy and pedagogy, Aoki's argument seems accurate. Garner (1972) describes a fable that offers some insight into our collective understanding of how knowledge is applied, one which he suggests frames a myth central to our culture 
that describes how we view the relationship between scientists and problem solvers who require information:

The fable is that scientists acquire knowledge, that this knowledge goes into the public domain, and that when a problem solver needs some knowledge to solve his problem, he extracts it from the public domain, uttering words of gratitude as he does so, and solves his problem. (p. 942)

The nature of the debate on literacy is clarified somewhat when exposed to this perspective, suggesting that negative responses to the scientific paradigm might be better seen as a challenge to the myth described by Garner. It should not be surprising that critics of this approach tend to draw attention to the simplicity of the scientific response, highlighting the omission of deeper, more complex explanations when dealing with human interaction. David Labaree (2000) points out that, while the soft knowledge produced by the humanities treads on less well-defined intellectual terrain and tends to be less prestigious, the broader scope of the research allows it to be more useful in fields such as education. Research focussed on establishing scientific credibility, on the other hand, necessarily needs to "zero in on the effects of a particular treatment," and in doing so is "also likely to be [more] trivial, since real education takes place in extraordinarily complex settings where variables are inextricably intermingled" (p. 65).

Barbara Foorman has written that "debates often end when paradigms shift" (1995, p. 15), and some argue this is what we have witnessed in recent years, as the evidenced-based, scientific authority of broad literature reviews such as the one conducted by the NRP have concluded an emphasis on the code is the best approach for teaching reading. The impressive political support that has translated into policy in many areas - most notably in the United States - is further evidence that there has been a paradigm shift in some areas.

Interestingly, we witness the continuation of the debate on literacy, even as the first evaluations of the Reading First program are being made public. Reading First is a federal program in the United States, mandated under the No Child Left Behind Act. The program allocates monies to Title 1 schools based on their implementation of scientifically based research on reading - the kinds of research highlighted in the 2000 report by the National Panel on Reading. In the U.S. government's own interim report (Gamse, Bloom, Kemple, \& Tepper Jacob, 2008), the effects of a code emphasis approach fall far short of the intended goals. And, not surprisingly, articles are appearing to point out the failure of scientific, evidence-based research in 
dictating curricula (for example, Kennedy Manzo, 2008). While critics say that the billion dollars per year spent by the U.S. government has not affected students' reading comprehension, supporters of the program continue to argue that funding should continue, and that the problem lies in faulty implementation, not pedagogical approach (Kennedy Manzo, 2008, p. 2). What is evident in this debate is that there remain fundamental differences in terms of both what kinds of research opposing paradigms feel should be informing educational policy, and, importantly, what skills and knowledge opposing camps argue are central to the teaching and learning of reading.

\section{The importance of reading to literacy}

At the core of the debate over how best to teach reading are competing understandings of what reading is in the first place and what function it plays within literacy development. The differing research paradigms begin with alternate understandings of the kinds of cognitive processes involved in learning how to read. Researchers who support a meaning-centered approach to reading, which has been categorized either fairly or not as emerging from a "constructivist, hermeneutic phenomenology and from critical theory" (Foorman, 1995), hold that people learn to read in much the same manner as they learn to speak; reading, they suggest, is a natural phenomenon (K. S. Goodman \& Y. M. Goodman, 1979; Smith, 2004). Goodman and Goodman (1979) argue that the process of learning how to read requires us to consider the nature of people in general, and children in particular, who learn how to read because of the natural desire to make sense of the world around them: "The reason is need. Language learning, whether oral or written, is motivated by the need to communicate, to understand and be understood" (1979, p. 138). The view that reading is natural extends to inform instruction. In fact, they suggest that teaching in the conventional sense is not needed: "Instruction does not teach children to read," they maintain: "Children are in no more need of being taught to read than they are of being taught to listen. What reading instruction does is help children to learn" (1979, p. 140). From this perspective the best teaching involves the creation of the best environment, one in which language users necessarily bring their own understandings and curiosity to the reading process in order to make meaning from it (Newman, 1985). Without purpose, without the social context, neither spoken communication nor reading provides the driving force that lures children to apply the energy needed to decode and use language. 
The argument that reading is natural presents a convincing, holistic view of children and learning that links learning to our personal experiences and social realities. Moreover, it centres learning in the affective domain, in which purpose, meaning construction, and individuality play a key role. There have been, however, hundreds of studies that seek to disprove the notion that reading is natural and all that such a view implies for teaching. Where the teaching of reading from the meaning-centred perspective is often referred to as top down, focussing on meaning first, proponents who argue for a code-breaking emphasis approach the teaching of reading from a bottom-up methodology (Adams \& Bruck, 1993). They begin with the fragmented components of textual decoding, and assume understanding comes later. The central, recurring point that underlies arguments from this camp is the belief that without the ability to decode the meaning of written letters and words in print, comprehension will be impossible. To researchers who argue for the need to teach decoding early and explicitly, it is absurd to suggest that the letters on a page do not represent a specific message encoded within a set phonological system for a specific purpose; the notion that texts have "no independent meaning seems like errant, if not pernicious, nonsense" (Gough, 1995, p. 84). To imply that meaning is guessed at through a set of clues is to ignore the very system in which the message is coded. The assertion that language processes are "limited to semantics, syntax, and pragmatics" (Liberman \& Shankweiler, 1991, p. 12) misses the mark altogether: "They seem not to consider that before one can get to the meaning or get to the words, whether one is a beginning or a skilled reader, one must understand the alphabetic principle" (p. 12). And, there are hundreds of studies examining all aspects of the decoding process to support these claims. Gough (1977) has examined the minutia of eye movements in the process of reading to establish that readers attend to individual words-even to individual letters (1977, p. 513). Others have examined the importance of phonemic knowledge as a critical factor in learning how to read (see for example, Perfetti, 1991). Many researchers have addressed the significance of phonemic awareness, establishing an important link between an early awareness of rhyme and alliteration and later reading and spelling ability (see for example, Bradley \& Bryant, 1983). Some researchers have attacked the problem from a different angle, arguing that there is abundant evidence that children who do not achieve an adequate level of decoding ability by the time they are in grade one are at significant risk of being weak, less engaged readers in later years. To advocates of teaching decoding, it is the power of decoding itself that leads to comprehension, not the other way around (Foorman, 1995, p. 55; Gough \& Juel, 1991).

Simply put, reading is not considered a natural act (Gough, 1980; Gough \& Juel, 1991; Stanovich, 1991); rather, it is something that must be learned. It is a skill that 
allows the reader to access meanings encoded in print. Not surprisingly, authors in this camp argue that to suggest spoken language and literacy develop in similar fashion is of little use.

Again, we are struck by the profound dissimilarities in the psychogenesis of language and literacy. To say they emerge as part of a common developmental pathway is to rob from the notion of natural its psychological frame of spontaneously occurring, biologically given, and maturationally driven. (Foorman, 1995, p. 6)

One of the challenges in sifting through the arguments of opposing research paradigms lies in the allure that a scientific approach seems to offer.Ted Aoki writes of a difficulty in distancing himself from the paradigm that is favored within his own culture (Aoki, 1986/99, p. 126), a reality that likely affects us all; however, even with this in mind, the arguments typified by Adams and Bruck, Liberman, Stanovich, and Foorman ring true. We may well recognize the fact that Western culture and thought have a preference for the scientific, the instrumental, the verifiable, but that does not mask the tendency we probably have to feel comfort in such an approach. Theorists who argue from a scientific platform are convincing in suggesting that if reading print were natural - at least in the way we understand oral language to bethen it would be less difficult to learn, and there would not be so many people who have trouble doing it. If we want to attend to reading, we need to consider that the mountain of research from the scientific paradigm has significant insight to offer. In effect, it is reasonable to acknowledge that both the code-breaking emphasis and the meaning-centered emphasis are correct in their arguments, but that they are not always discussing the same thing.

Finding a scientific answer to the question of how to teach reading and literacy has significant cultural and political appeal, and has no doubt resulted in a great deal of research being discounted in recent years. But, even if we accept this as a reasonable interpretation of the current state of affairs, and conclude that errors have been made in how code-emphasis research has been used to inform policy, it is very difficult, and probably unwise, to reject the results en masse of the work from the evidence-based research paradigm. There is, for example, convincing evidence that not all children learn to read in the same way or have the same kinds of instructional needs. Some children have good decoding skills, but require significant work on comprehension, while others clearly have a good ability with comprehension of complex ideas, but experience difficulty at the decoding phase (Aaron, Joshi, \& Williams, 1999, p. 125). Another point of caution in discounting a code-emphasis pedagogy is that 
weaker readers, who are more likely to come from lower socioeconomic backgrounds, tend to benefit more from explicit instruction in code breaking, and risk being left behind in a classroom that does not attend explicitly to strategies and skills (Pinnell, 1989). This phenomenon, referred to as "the Mathew effect" (A. E. Cunningham \& Stanovich, 1997, p. 934), is observed when early reading exposure gives some students a notable advantage in school, and that within a strictly wholelanguage classroom this advantage generates rewards, followed by greater enthusiasm, followed by further success. Students entering school with little or no reading exposure are at risk of falling into a cycle of frustration and failure as they lag behind their peers and experience little success.

We construct definitions to serve our purposes, but we are at some level bound by the definitions that we create. Whether by design or by inertia, definitions of reading and literacy have evolved-or remained the same in some circles-to allow for many things. The belief, for example, that literacy equals reading, that it is apolitical, that it is equally accessible to everyone (Gough, 1995), has enormous implications for pedagogy and for our commonplace beliefs of who is responsible when there is failure in the system. Viewing literacy from this perspective suggests that failure to become literate is a failure of the individual, not of society (Hull, 1993). If the essential component of literacy is reading (meaning decoding text) then the development of literacy is freed from any cultural or political baggage; a failure to succeed might be a failure of the teacher, or of the student, but it does not imply any social advantage to a particular culture or class. Phillip Gough (1995) argued that it is through a separation of literacy from politics that we ensure all students are treated equally. Gough's suggestion is that by approaching literacy as a technical skill, as decoding text, we make it apolitical and give all students equal access to it. This argument may have some common-sense appeal, but it ignores the evidence that literacy is a complex, culturally determined practice. It ignores the fact that in treating all students equally in spite of differing needs we are not promoting equity at all.

\section{Balanced Literacy}

Given that arguments about how to teach literacy are as much about approaches to research and knowledge as they are about pedagogy, it seems unlikely that we will see an end to the debates on reading without a paradigm shift. An alternate solution is hinted at by Garner (1972, p. 942) in suggesting that perhaps we need to approach the problem from the opposite perspective; that is, it may be more advantageous for the scientist to be in touch with the people who have the questions than the other way around. Michael Pressley (Pressley, Roehrig, Bogner, Raphael, \& 
Dolezal, 2002; Pressley, Wharton-McDonald, \& Mistretta Hampston, 2006) has made a similar suggestion. Instead of examining aspects of reading in isolation, or of approaching literacy from a theoretical model alone, Pressley and his team studied highly effective teachers with a view to finding commonalities in method, and found that there is a great deal to be learned from teachers. Interestingly, almost all the teachers involved in the study reported that they "identified, at least to some degree" (Pressley et al., 2006, p. 243) with a whole-language approach. That is, they stressed the value of a rich literacy environment in which the students would engage with reading in a wide variety of meaningful ways. Other commonalities amongst the teachers selected included fostering a) positive classroom environments, b) little competition within the class, c) clear classroom routines, d) a variety of teaching configurations (modelled, shared, guided, independent learning), e) a mixture of direct skills instruction and whole-language-type instruction, and $f$ ) encouragement of parental participation (p. 250). Notably, the teachers did not feel skills instruction and whole language were antithetical in any way; rather, reading skills were taught both in context and through explicit decontextualized approaches such as games and spelling tests (p. 244): "These teachers were emphatic in stating that whole language and skills instruction are not contradictory but, rather, complementary approaches in their instruction of struggling beginning readers" (Pressley et al., 2002, p. 3).

Pressley's findings, along with the work of others, begin to define the notion of a balanced literacy (Allington, 2001; P. M. Cunningham \& Allington, 2007; Pressley et al., 2002) - at the simplest level an amalgamation of the opposing sides of the great debate-and for some (Spiegel, 1998) an end point to the ongoing problem of how to teach reading and literacy. The notion of balanced literacy accepts that children become literate through a variety of means and practices simultaneously, and not through only a skill-centered instruction or a whole-language environment in isolation. Yet, in spite of this seeming compromise, the debate continues to flourish. The problem, in part, is that there is some uncertainty about what we mean by "balance" when we speak of literacy. At one level the term is used to describe an effort to find a middle zone between various dichotomies: first among them perhaps being the gulf between whole language and explicit strategy and skill instruction (Fitzgerald, 1999), but it also refers to the need to balance explicit teaching with learner-directed discovery; between whole group and small group work; between unplanned and planned instruction. The haziness Fitzgerald speaks of has allowed the concept of balance to be used to describe vastly different programs. Constance Weaver (1998b) warns us that the research of the last thirty years is being misused, and that what in many places is being touted as balanced literacy is far closer to a phonics-first model. They threaten, she says, "to maintain or restore an old imbalance in the opposite 
direction: too much skills work, and too little thoughtful reading and discussion of texts read" (p. 12). The result is the implementation of mandated policies either by district offices or government agencies that are based on a misuse and misunderstanding of narrow, segmented components of research: "They do not understand that good teaching requires knowledgeable teachers able to teach flexibly, not locked into a mandated methodology or a prepackaged curriculum" (p. 13). Weaver's caution reminds us that the concept of balance means far more than a simple compromise between code-breaking and whole language perspectives. In recognizing both the social complexity and the presence of diverse learning styles, balanced literacy highlights teaching approaches as well as content. A balanced approach ensures students experience several learning contexts that vary in their level of support: these typically include modeled reading and writing, shared reading and writing, guided reading and writing, and independent reading and writing -all of which are supported through whole-group, small-group, and independent practice (Brailsford, 2002; Fountas \& Pinnell, 1996). Underpinning the concept of balance is the belief that students learn best through a variety of experiences, and through a gradual release of independence that moves from modeled toward independent learning (Brailsford, 2002).

Descriptions of balanced literacy demonstrate an understanding that literacy must be fostered in a complex environment that attends to both the skills and strategies needed to decode, as well as to the more complex affective domain that leads to high levels of engagement and sophisticated understandings. Researchers working on the concept of balance (Allington, 2001; P. M. Cunningham, Hall, \& Sigmon, 1999; Fountas \& Pinnell, 1996; Pressley, 2006) recognize that reading requires explicit teaching (for example, Fountas \& Pinnell, 1996, p. 1), and that explicit instruction within a diverse environment allows students who arrive with little reading exposure to thrive alongside stronger readers (P. M. Cunningham, 2003; P. M. Cunningham et al., 1999). They are unequivocal as well in arguing that attending to reading can be done well (in context) within a rich, whole-language environment (Fountas \& Pinnell, 1996). In other words, the suggestion by researchers who argue that a whole-language environment necessarily ignores the need to teach reading skills seems unfounded in light of successful teachers' experiences with balanced literacy programs (for positive case studies, see Bitter, O'Day, Gubbins, \& Socias, 2009; P. M. Cunningham, Hall, \& Defee, 1998; Dicembre, 2002). Similarly, the arguments suggested by Goodman and Goodman, and Smith are equally weakened by evidence demonstrating a high level of engagement within a classroom that attends to reading skills explicitly. Strangely, what began as an argument regarding opposing approaches is reframed within the idea of balance to suggest that a program that omits either perspective will be ineffective-both paradigms, it seems, hold part of the answer. 


\section{Conclusion}

Very likely, the paradigm shift Foorman spoke of will not come about as a result of any new research on reading or literacy. The problem is not that researchers are coming up with the wrong answers; instead, we need to consider the possibility that they have tended to ask the wrong questions, or, at the very least, that they have in some cases attempted to address exceptionally complex questions through a narrow lens. More complete answers may be found by considering Wendel Garner's advice and abandoning our worship of researchers as holders of knowledge, and by encouraging academics and teachers to reflect in concert on what seems to work in classrooms. The nature of the communication between researchers and teachers might be better served by considering the relationship as a reciprocal, flexible partnership rather than as a unidirectional source of guidance. In this sense, research from both paradigms can inform what teachers do and how they reflect on their practice without prescriptive blindness to dissimilar realities. A balanced approach acknowledges the unique nature of classrooms that require as much attention to how any one teacher will succeed in fostering engagement as to what they ought to be teaching: context, approach, and content are considered collectively, rather than in isolation. The point is that we do not need to adhere to any one paradigm, but to pay heed to the insights each has to offer in light of the definition of literacy that we choose to adopt. Indeed, the sheer volume of research into this debate is staggering, and while there seems to be some tendency to suggest the debate is over and to continue to argue for one side or the other, the more germane question for us to pursue is, "What knowledge can we exploit from the research on both ends of the continuum in order to support literacy learning?"

\section{References}

Aaron, P. G., Joshi, M., \& Williams, K. A. (1999). Not all reading disabilities are alike. Journal of Learning Disabilities, 32(2), 120-137.

Adams, M. J., \& Bruck, M. (1993). Word recognition: The interface of educational policies and scientific research. Reading and Writing: An Interdisciplinary Journal, 5, 113-139.

Allington, R. (2001). What really matters for struggling readers: Designing researched-based programs. New York: Addison-Wesley Educational Publishers Inc.

Allington, R. (2004). Setting the record straight: Federal officials are holding schools to impossible standards based on misinterpretations of the research. Educational Leadership.

Aoki, T. T. (1984). Competence in teaching as instrumental and practical action: A critical analysis. In W. F.Pinar \& R. Irwin, L. (Eds.), 
Curriculum in a new key: The collected works of Ted Aoki. Mahwah, NJ: Lawrence Erlbaum Associates.

Aoki, T. T. (1986/99). Interests, knowledge, and evaluation: Alternative approaches to curriculum evaluation. In W. F. Pinar \& R. Irwin, L. (Eds.), Curriculum in a new key: The collected works of Ted T. Aoki. Mahwah, NJ: Lawrence Erlbaum Associates.

Bitter, C., O'Day, J., Gubbins, P., \& Socias, M. (009). What works to improve student literacy achievement? An examination of instructional practices in a balanced literacy approach. Journal of Education for students placed at risk (JESPAR), 14(1), 17-44.

Bradley, L., \& Bryant, P. E. (1983). Categorizing sounds and learning to read--a causal connection. Nature, 301(3), 419-421.

Brailsford, A. (2002). Balanced Literacy Division 1. Edmonton, Alberta: Edmonton Public Schools Resource Development.

Camilli, G., \& Wolfe, P. (2004). Research on reading: A cautionary tale. Educational Leadership.

Carbo, M. (1988). Debunking the great phonics myth. Phi Delta Kappan, 70(3), 226-240.

Chall, J. S. (1967). Learning to read: The great debate. Fort Worth: Harcourt Brace College Publishers.

Cunningham, A. E., \& Stanovich, K. E. (1997). Early reading acquisition and its relation to reading experience and ability 10 years later. Developmental Psychology, 33(6), 934-945.

Cunningham, P. M. (2003). What research says about teaching phonics. In L. Mandel Morrow, L. B. Gambrell \& M. Pressley (Eds.), Best practices in literacy instruction (pp. 65-86). New York: The Guilford Press.

Cunningham, P. M., \& Allington, R. L. (2007). Classrooms that work: They can all read and write. Boston: Pearson.

Cunningham, P. M., Hall, D. P., \& Defee, M. (1998). Nonability-grouped, multilevel instruction: Eight years later. The Reading Teacher, 51(8), 652-664.

Cunningham, P. M., Hall, D. P., \& Sigmon, C. M. (1999). The teacher's guide to the four blocks. Greensboro, North Carolina:Carson-Dellosa.
Dicembre, E. (2002). How they turned the ship around. Journal of Staff Development, 23(2), 32-35.

Fitzgerald, J. (1999). What is this thing called "balance?" The Reading Teacher, 53(2), 100-106.

Foorman, B. R. (1995). Research on "the great debate": Code-oriented versus whole language approaches to reading instruction. School Psychology Review, 24(3).

Fountas, I. C., \& Pinnell, G. S. (1996). Guided reading: Good first teaching for all children. Portsmouth, $\mathrm{NH}$ : Heinmann.

Gamse, B. C., Bloom, H. S., Kemple, J. J., \& Tepper Jacob, R. (2008). Reading first impact study: Interim report (NCEE 2008-4016). Washington, DC: National Center for Education Evaluation and Regional Assistance, Institute of Educational Sciences, U.S. Department of Education.

Garan, E., Shanahan, T., \& Henkin, R. (2001). What does the report of the national reading panel really tell us about teaching phonics? Language Arts, 79(1), 61-71.

Garner,W.R. (1972). The acquisition and application of knowledge: A symbiotic relation. American Psychologist, 941-946.

Goodman, K. S., \& Goodman, Y. M. (1979). Learning to read is natural. In L. B. Resnick \& P. A. Weaver (Eds.), Theory and practice of early reading (Vol. 1, 137-154). Hillsdale, NJ: Lawrence Erlbaum Associates.

Gough, P. B. (1977). One second of reading. In H. Singer \& R. B. Ruddell (Eds.), Theoretical models and processes of reading ( $2^{\text {nd }}$ ed.). Newark, Delaware: International Reading Association.

Gough, P. B. (1980). Learning to read: An unnatural act. Bulletin of The Orton Society, 30, 179-196.

Gough, P. B. (1995). The new literacy: Caveat emptor. Journal of Research in Reading, 18(2), 79-86.

Gough, P. B., \& Juel, C. (1991). The first stages of word recognition. In L. Rieben \& C. A. Perfetti (Eds.), Learning to read: Basic research and its implications. Hillsdale, NJ: Lawrence Erlbaum Associates. 
Halliday, M. A. K. (1978). Language as social semiotic: the social interpretation of language and meaning. Baltimore: University Park Press.

Hull, G. (1993). Hearing other voices: A critical assessment of popular views on literacy and work. Harvard Educational Review, 63(1), 21-49.

Kennedy Manzo, K. (2008). Reading first doesn't help pupils 'get it'. Education Week, 27(36), $1-14$.

Krashen, S. (2001). More smoke and mirrors: A critique of the national reading panel report on fluency. Phi Delta Kappan.

Labaree, D. F. (2000). Educational researchers: Living with a lesser form of knowledge. In C. Day, A. Fernandez, T. E. Hauge \& J. Moller (Eds.), The life and work of teachers: International perspectives in changing times. London: Falmer Press.

Liberman, I. Y., \& Shankweiler, D. (1991). Phonology and beginning reading: A tutorial. In L. Rieben \& C. A. Perfetti (Eds.), Learning to read: Basic research and its implications (pp. 3-17). Hillsdale, NJ: Lawrence Erlbaum Associates.

Ministère de l'Éducation du Québec (2001). Programme de formation de l'école québécoise: Éducation préscolaire, enseignement primaire. Québec: Gouvernement du Québec.

National Reading Panel (2000a). [Executive summary] Teaching children to read: An evidenced-based assessment of the scientific research literature on reading and its implications for reading instruction. Washington, DC: National Institute of Child Health and Human Development.

National Reading Panel (2000b). Teaching children to read: An evidence-based assessment of the scientific research literature on reading and its implications for reading instruction. Washington, DC: National Institute of Child Health \& Development.

Newman, J. M. (1985). Insights from recent reading and writing research and their implications for developing whole language curriculum. In J. Newman, M. (Ed.), Whole language: Theory in use. Portsmouth, New Hampshire: Heinemann.
Perfetti, C. A. (1991). Representations and awareness in the acquisition of reading competence. In L. Rieben \& C. A. Perfetti (Eds.), Learning to read: Basic research and its implications. Hillsdale, NJ: Lawrence Erlbaum Associates.

Pinnell, G. S. (1989). Reading recovery: Helping at-risk children learn to read. The Elementary School Journal, 90(2), 161-183.

Pressley, M. (2006). Reading instruction that works: The case for balanced teaching (third ed.). New York: The Guilford Press.

Pressley, M., Roehrig, A., Bogner, K., Raphael, L. M., \& Dolezal, S. (2002). Balanced Literacy Instruction. Focus on exceptional children, 34(5), 1-14.

Pressley, M., Wharton-McDonald, \& Mistretta Hampston, J. (2006). Expert primary-level teaching of literacy is balanced teaching. In M. Pressley (Ed.), Reading instruction that works: The case for balanced teaching (third ed.). New York: Guilford Press.

Smith, F. (2004). Understanding reading: A psycholinguistic analysis of reading and learning to read (sixth edition). Mahwah, New Jersey: Lawrence Erlbaum Associates.

Spiegel, D. L. (1998). Silver bullets, babies, and bath water: Literature response groups in a balanced literacy perspective. The Reading Teacher, 52(2), 114-124.

Stanovich, K. E. (1991). Changing models of reading and reading acquisition. In $L$. Rieben \& C. A. Perfetti (Eds.), Learning to read: Basic research and its implications. Hillsdale, NJ: Lawrence Erlbaum Associates.

Weaver, C. (1998a). Experimental research: On phonemic awareness and on whole language. In C. Weaver (Ed.), Reconsidering a balanced approach to literacy. Urbana, Illinois: National Council of Teachers of English.

Weaver, C. (1998b). Toward a balanced approach to reading. In C. Weaver (Ed.), Reconsidering a balanced approach to reading. Urbana, Illinois: National Council of Teachers of English. 


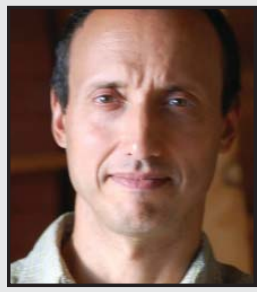

Paul Kettner spent twelve years as an English language arts teacher, and is now a literacy consultant at the English Montreal School Board working with teachers and administrators at both the elementary and secondary level. He is currently involved in implementing a large-scale, early literacy initiative that combines the objectives of improving student engagement and outcomes, as well as fostering sustainable, collaborative teacher learning. Paul is also a doctoral candidate at McGill University, Montreal, Quebec. His research interests include literacy, teacher education, and school-based change. 